\title{
Bem Viver: discussões teórico conceituais ${ }^{*}$
}

\author{
Buen Vivir: discusiones teóricas conceptuales \\ Good Living: conceptual theoretical discussions \\ Liliane Cristine Schlemer Alcântara ${ }^{1}$ Isabel Jurema Grimm² \\ Carlos Alberto Cioce Sampaio ${ }^{3}$ Oklinger Mantovaneli Júnior ${ }^{4}$ \\ Shimene Feuser ${ }^{5}$ Manon Carcia ${ }^{6}$ \\ Recibido: 21/11/2016 / Aceptado: 23/5/2017 \\ Resumo
}

\begin{abstract}
O Bem Viver nos territórios andinos e amazônicos provém de uma existência de milhares de anos, sobrevivendo como um processo prático alternativo, construído frente a um modelo de desenvolvimento dominante. Neste contexto, a ecossocioeconomia emerge de desafios contemporâneos para pensar sociedades sustentáveis, diferentemente do que se constitui atualmente como sociedade de consumo, individualista e instrumental. O artigo busca debater questões do referencial teórico sobre o Bem Viver, dialogando com práticas econômicas sustentáveis. Metodologicamente, utilizase de pesquisa com revisão teórica e abordagem interdisciplinar, a partir das categorias dialéticas da subjetividade, coletividade e dinâmica ser humano-natureza. Os resultados evidenciam um constructo teórico que releva abordagem interdisciplinar, intercultural, sobretudo quando o tema do Bem Viver possa representar formas de vida de comunidades tradicionais da Americana Latina. Evidenciam também um olhar sistêmico, para-econômico (além da visão do consumo) sobre o Bem Viver.
\end{abstract}

Palavras-Chave: Bem Viver, desenvolvimento, interculturalidade, interdisciplinaridade.

\begin{abstract}
*Este texto corresponde con la temática de la ponencia presentada en el III Seminario Internacional Culturas y Desarrollo, III Encuentro de la Red de Interculturalidad, IV Encuentro de la Red de Trabajo con Pueblos Indígenas, IV Encuentro sobre Sociedades en Cambio, Territorios, Culturas y Buen Vivir, Desafíos desde las identidades y Saberes Diversos, realizado el 20, 21 y 22 de julio de 2016, en la Universidad Nacional, campus Omar Dengo, Heredia y en la Universidad de Costa Rica, Sede de Occidente, San Ramón, ahora en formato de artículo científico, en versión completa extendida.
\end{abstract}

${ }^{1}$ Posdoctoranda del Programa de Posgrado en Gestión Urbana. (PPGTU). Profesora, doctora en Desarrollo Regional del Centro de Ciencias Agrarias (CCA), Brasil. http://orcid.org/0000-0001-8502-720X. Correo electrónico: lilianecsa@yahoo.com.br

${ }^{2}$ Doctora en Medio Ambiente y Desarrollo / Universidad Federal de Panamá - UFPR. Post-Doctoranda en Gestión Ambiental Universidad Positivo - UP, Brasil. Correo electrónico: isabelgrimm@gmail.com

${ }^{3}$ Doctor en Ingeniería de Producción / UFSC con énfasis en Economía Social por la École de los Hautes Études en Ciencias Sociales, Francia. Posdoctor en Ciencias Ambientales / Washington State School, EUA, en Cooperativismo Corporativo / MU, España, y en Ecosoecionomía/Universidad Austral de Chile. Profesor de los Programas de Postgrado (PPG) en Desarrollo Regional / Universidad Regional de Blumenau - FURB, Gestión Ambiental / Universidad Positivo (UP) y en Medio Ambiente y Desarrollo / UFPR. Visitante del PPG en Desarrollo a la Escala Humana y Economía Ecológica / UACh. Investigador CNPq. Coordinador Adjunto del Área en Ciencias Ambientales / CAP. Universidad Regional de Blumenau (FURB) e Universidade Positivo (UP), Brasil. Correo electrónico: carlos.cioce@gmail.com

${ }^{4}$ Doctor en Sociología/UNESP. Profesor del PPGDR/FURB/ Líder Núcleo de Políticas Públicas (NPP). Investigador/CNPq, Brasil Correo electrónico: oklingerfurb@gmail.com

${ }^{5}$ Doctoranda en Desarrollo Regional/FURB. Universidad Regional de Blumenau (FURB). Investigadora del Núcleo de Participación de Políticas Públicas, Brasil. Correo electrónico: eng.shimene@gmail.com

${ }^{6}$ Doctoranda em Gestión Urbana/PUCPR/ Investigadora Núcleo en Ecosocioeconomia Pontifícia Universidade Católica do Paraná (PUC), Brasil. Correo electrónico: manongarcia@yahoo.com.br 
Resumen

El "Buen Vivir" en los Andes y territórios amazónicos resultan de miles de años, sobreviviendo como fruto de un proceso práctico alternativo, construído en sentido contrário al de un modelo de desarrollo dominante. En este contexto, la ecosocioeconomia surge de los desafíos contemporáneos que piensan en sociedades sostenibles, a diferencia de lo que constituyen actualmente la sociedad de consumo, individualista e instrumental. El artículo trata de analizar temas de referencias teóricas sobre el Buen Vivir, dialogando con las prácticas económicas sostenibles. Metodológicamente, se utiliza la investigación en esta crítica teórica y enfoque interdisciplinar, desde las categorías dialécticas de la subjetividad, los seres humanos colectivos y dinámicos y la naturaleza. Los resultados muestran una construcción teórica que encaja en un enfoque interdisciplinario, intercultural, especialmente cuando el tema de vivir bien, puede representar formas de vida de las comunidades tradicionales en América Latina. También muestra una perspectiva sistémica, paraeconómica (además de la visión de consumo) del "Buen Vivir

Palabras clave: Buen Vivir., desarrollo, interculturalidad, interdisciplinariedad.

\title{
Abstrac
}

\begin{abstract}
The Good Living in the Andean and Amazonian territories comes from a thousands of years lifetime, surviving as an alternative practical process, built against a dominant development model. In this context, eco-socioeconomics emerges from contemporary challenges to think of sustainable societies, unlike what is now constituted as a consumer, individualistic and instrumental society. The article seeks to discuss issues of the theoretical reference on the Good Living, dialoguing with sustainable economic practices. Methodologically, research is used with theoretical revision and interdisciplinary approach, from the dialectic categories of subjectivity, collectivity and human-nature dynamics. The results show a theoretical construct that emphasizes an interdisciplinary and intercultural approach, especially when the theme of the Good Living can represent forms of life of Latin American's traditional communities. They also show a systemic, para-economic (besides the consumption vision) look at Good Living.
\end{abstract}

Key Words: Good Living, development, interculturalism, interdisciplinarity.

\section{Introdução}

Discussões e estudos sobre a questão ambiental têm se demonstrando emergentes, em especial em torno do resultado das agressões ao ecossistema, que refletem no espaço social, um território de diversas culturas, identidades, tradições, hábitos e modos de vida. Sob a perspectiva social, a baixa qualidade de vida e bem-estar da população dos países em desenvolvimento, demonstra ausência de equidade, solidariedade e justiça social (Sachs, 2007).

A problemática ambiental, tem sua gênese no processo de expansão do modo de produção capitalista, dos padrões tecnológicos que visam maximizar os ganhos em curto prazo gerando efeitos econômicos, ecológicos e culturais desiguais na sociedade onde o que serve para um não serve para $o$ outro (LEFF, 1994). Este modelo de desenvolvimento excludente, caracterizado, no início, pelo alto grau de industrialização dos diferentes processos produtivos e pelo crescimento exponencial dos recursos tecnológicos utilizados naqueles processos, produziu como resultado uma sociedade alicerçada em uma racionalidade economicista-utilitaristaconsumista (Sampaio, 2005).

O desenvolvimento econômico e material são elementos importantes, mas, insuficientes para a promoção do desenvolvimento humano. Um modelo de desenvolvimento que configure na equidade e na justiça social, deve partir da ação efetiva que não se resuma à mera teoria. Vivenciar as questões ambientais é o primeiro passo para a transformação do comportamento social.

Assim iniciativas que visem processos de mudanças de hábitos das pessoas - uma herança cultural difícil de ser revertida - criam alternativas para, ao menos, amenizar todos os efeitos nocivos 
da ação humana no planeta. Medidas simples, mas capazes de reverter processos de comportamento, cultura de consumo e a maneira de encarar o futuro, sendo cada indivíduo a mudança que se necessita para o mundo melhor.

Portanto, o desenvolvimento não pode ser compreendido e conduzido de maneira linear, ao contrário deve ser uma rede de co-desenvolvimentos interdependentes com novas alternativas, que produzam auto dependência, auto sustentação e participação proporcionando condições básicas para a inter-relação dos seres humanos, natureza e tecnologia (Sachs, 2007).

Ações advindas de determinados conhecimentos locais possibilitam maior integração entre a produção sustentável, em atendimento às necessidades básicas das comunidades e, assim, a melhoria da sua qualidade de vida. Neste sentido é que a interculturalidade propõe uma possível busca de novas aprendizagens no espaço social do cotidiano da identidade cultural de cada território, por meio da interação, diálogo e reciprocidade entre os diferentes grupos sociais (Foroni, 2005).

Ao mesmo tempo, as alternativas ecossocioeconômicas $^{7}$ são experiências em curso, atividades de grupos organizados ou quase organizados, que convergem uma nova ação social norteada por uma racionalidade mais valorativa de gestão em nível interorganizacional participativo, descentralizado e, ainda, social e ambientalmente responsável conduzido e pautado por critérios extraorganizacionais que demonstrem efetividade na prática de suas atividades em resposta ao desenvolvimento sustentável (Sampaio, 2010).

Teoria recente e interdisciplinar, a ecossocieconomia é utilizada para denominar e demonstrar experiências que evidenciam que é possível colocar em prática outra gestão que resultem no desenvolvimento sustentável, valorizando novas práticas econômicas, no sentido de incorporar no processo de tomada de decisão a dimensão socioambiental, o que na maioria das vezes possui mera predominância da lógica mercantil (Grimm et al., 2016).

Neste contexto, emerge o diálogo em torno do Bem Viver (BV), que representa uma cosmovisão construída ao longo de muitos anos pelos povos altiplanos dos Andes e incorpora uma ação coletiva que propõe uma visão de sociedade e de economia alternativa para repensar o conceito de desenvolvimento.

Esta discussão remete à visão ecocêntrica, onde sugere que o sistema social está interconectado ao ecológico, sobretudo na ocasião que se considera a promoção do BV para gerações futuras. Para fins metodológicos, este estudo adota uma perspectiva teórica, com abordagem interdisciplinar, a partir das categorias dialéticas da subjetividade e coletividade e da dinâmica homem-natureza.

O artigo busca debater questões do referencial teórico sobre o Bem Viver, dialogando com práticas econômicas sustentáveis. Não se pretende aprofundar os antecedentes históricos do desenvolvimento ou discutir a teoria do desenvolvimento sustentável e sua prática, mas tratar um sinótico contexto teórico sobre o Bem Viver a partir de uma abordagem interdisciplinar e intercultural sobre o tema.

\footnotetext{
${ }^{7}$ A origem do termo ecossocioeconomia se deu pelo economista alemão Karl Willian Kapp (1963), ao tratar dos impactos ambientais relacionados às organizações. O termo foi difundido pelo economista polonês naturalizado francês Ignacy Sachs, devido sua visão de desenvolvimento imbricado na concepção de equidade no crescimento econômico e social, bem como no cuidado com a questão ambiental.
} 


\section{Gênese do conceito}

O destaque dado ao tema do Bem Viver a nível global, tem relação direta ao fato dos governos do Equador (2008) e Bolívia (2009) terem incluído a temática em suas Constituições, onde estabeleceram os direitos de la Madre Tierra (PachaMama). Surgida do discurso pós colonialistas crítico do modelo desenvolvimentista ocidental, e das cosmovisões os povos indígenas do altiplano, se configura como uma filosofia de vida cujo valor fundamental está conectado ao bem maior de preservação da natureza e no direito das comunidades de viverem de acordo com suas tradições.

De acordo como Ortiz (2012), Bock (2013), Coraggio (2014) e Santos (2014), o conceito de Bem Viver origina-se dos povos andinos, em especial dos Quéchua (no Equador, cuja expressão na sua língua materna é Sumak kawsay) e Aimará (na Bolívia, significa Suma Qamaña). Diante disso, o Bem Viver não é apenas um conceito utópico, é uma forma de vida substantiva, esse modo diferenciado de viver está fundamentado em três pilares da convivialidade ${ }^{8}$ : viver bem com o outro, natureza e espírito.

Bock (2013) disserta Bem Viver, segundo a cosmovisão indígena: (i) Bem Viver se relaciona com senso de territorialidade e natureza: relação com a terra, natureza, possui significado indispensável na organização do modo de viver indígena. Todos os seres possuem vida. Por isso, o Bem Viver deve ser para todos os seres; (ii) Bem Viver imbrica-se com a Cultura: preserva-se a cultura dos antepassados e preocupa-se em transmiti-la; (iii) Bem Viver relacionase com a Economia: ter o alimento suficiente para o período presente. O excedente é compartilhado, não há acumulação; (iv) Bem Viver correlaciona-se com vida em Comunidade: ter respeito e compromisso como o outro.
O Bem Viver, não é um produto recente do processo político do início do século XXI nos países andinos. Ele parte de uma longa busca por uma vida alternativa, na qual, teve seu alicerce no calor das lutas populares, especialmente dos povos indígenas. Desta forma, o Bem Viver é um conjunto de práticas vivenciadas de resistência ao colonialismo e suas consequências.

É interessante observar que a discussão do Bem Viver esta em sintonia e reflete em várias partes do mundo, onde são questionados os fundamentos do progresso capitalista. "O próprio mundo está passando por um "mau desenvolvimento" generalizado, incluindo aqueles países considerados industrializados, ou seja, países na qual o seu estilo de vida servia como referência para países atrasados" (Segato, 2014: 177).

Para Coraggio (2014), a crítica realizada ao Bem Viver não passa de um equívoco usual, na qual, sua concretização só seria viável com o retorno das condições e o modo de vida do passado e para os críticos, dificilmente seria possível esse regresso na atualidade.Para o autor, o Bem Viver expressa construções e reconstruções que estão em curso, onde se interagem, mesclando conhecimentos e sensibilidades, na expectativa de modificar a estrutura do processo de desenvolvimento atual, ou encontrar um outro, com maior afinidade com as dinâmicas da natureza.

O Bem Viver, na verdade, é apresentado como uma oportunidade de construir e reconstruir coletivamente novas formas de vida. Ele é um passo qualitativo para dissolver o conceito tradicional de progresso que deriva de um desenvolvimento produtivista, sobretudo baseado na visão economicista do crescimento. Mas, não é só dissolver essa visão reducionista, o Bem Viver propõe um arcabouço mais rico em conteúdo e visão, e certamente mais complexo na busca de modelos de desenvolvimento que sejam ambientalmente mais sustentáveis e mais inclusivos do ponto de vista social, econômico e cultural.

\footnotetext{
${ }^{8}$ Capacidade de fazer conviverem dimensões de produção e cuidado, de efetividade e compaixão, de modelagem e criatividade, de liberdade e fantasia, de equilíbrio multidimensional e complexidade social (Illich, 1978).
} 
No campo da subjetividade, o Bem Viver incorpora no individuo o justo, o ético e o necessário. Não é uma atividade de poder, é uma ação coletiva capaz de maximizar a cidadania. É uma subjetividade que se projeta como participante, porque seu interesse não esta necessariamente no controle das ações do Estado. Neste caso, "o Bem Viver, como categoria analítica para compreender a vida, apresenta de forma direta, não a busca do poder, mas o sentido de agir sobre o poder não na dimensão jurídica, mas no universo cultural e subjetivo" (Alves e Albuquerque, 2013:155).

Desta forma, Segato (2014), afirma que a crítica realizada a temática Bem Viver recupera sua complexidade e interdisciplinaridade por meio da interculturalidade. $\mathrm{O}$ que é próprio das cosmologias originarias dos povos andinos. O Bem Viver, permite uma visão de sociedade e economia alternativa em contraposição ao conceito hegemônico de desenvolvimento, imposição cultural herdada do saber ocidental (Acosta, 2014). Para o autor:

El Buen Vivir, en tanto sumatoria de prácticas vivenciales de resistencia al colonialismo y sus secuelas, es todavía un modo de vida en varias comunidades indígenas, que no han sido totalmente absorbidas por la modernidad capitalista o que han resuelto mantenerse al margen de ella (p.37).

O Bem Viver apresenta questionamentos substanciais às ideias contemporâneas de desenvolvimento. Propõe novas formas de viver ancoradas no direito capital de suprir as necessidades fundamentais do ser humano, contrapondo à acumulação material, legado histórico do processo de colonização Latino Americana.

\section{Bem viver: interdisciplinaridade, interculturalismo e (des) colonialidade}

A abordagem da relação entre o saber local e o saber universal, imposto pela cultura dominante, é principal referência para proposição teórica da descolonização do saber. Para compreender o processo das relações entre saber local e saber pretensamente universal, imposto no contexto da globalização, reflexão a partir da perspectiva intercultural, é possibilidade de análise que permite descolonizar o saber e, consequentemente, o imaginário que o sustenta (Quijano, 2002).

Interculturalidade como perspectiva possibilita reconhecimento e valorização de outros sistemas culturais, numa relação de complementaridade que permite diálogo. Este, por sua vez, permite partilha de conhecimentos, para além de toda a falsa oposição entre moderno e tradicional.

Para Menezes (2011:328), "[...] a interculturalidade apresenta interrogações e novas perspectivas diante de um contexto em que perdemos a memória, a possibilidade do diálogo e a riqueza dos saberes". Essa reflexão permite questionar a separação natureza e cultura, posta em prática pela visão eurocêntrica centrada na racionalidade do positivismo, sobre a qual foram construídas a ciência e a tecnologia do mundo ocidental.

O debate sobre o Bem Viver, incluem diversas correntes e abrangem diversas questões entre elas a interdisciplinaridade e o interculturalismo, e a necessidade da descolonização do saber, tanto em sua dimensão social, na produção do conhecimento ou no que atesta a relação humana com a natureza, da qual decore processos de transformação próprias do modelo de desenvolvimento que pretende ser hegemônico.

Modelo este, mecanicista, que passou a caracterizar por um lado o que se conhece por paradigma hegemônico e por outro a crítica aos limites aos desafios 
para o reconhecimento da interdisciplinaridade com a alternativa de produzir conhecimento científico diante dacomplexidadedo mundocontemporâneo(Almeida,2011).

A interdisciplinaridade tem impulsionado mudanças no pensar e agir humanos, resgatando a visão de contexto da realidade, demonstrando que vivemos em constantes interações complexas. Recupera a tese de que todos os conceitos e teorias estão conectados entre si e considera a complementaridade dos processos, plenitude das relações, diálogo, problematização, atitude crítica e reflexiva, enfim, uma visão articuladora que rompe com o pensamento disciplinar, parcelado, hierárquico e fragmentado que marcou por muito tempo a concepção cartesiana de mundo (Thiesen, 2008).

Neste ponto Almeida (2011) sugere que a interdisciplinaridade busca responder pelos problemas gerados pelo avanço da ciência moderna disciplinar caracterizada como fragmentadora e simplificadora do real.

Para Japiassu (1976), a interdisciplinaridade propõe melhorias na identidade humana por meio da transição subjetiva para uma intersubjetiva, resgatando a ideia primeira de cultura, o papel da escola na formação do homem inserido em sua realidade e o papel do homem como agente de mudanças.

De acordo com Fazenda (1998), a interdisciplinaridade proporciona vantagens como o convívio com outras perspectivas, habilidade para avaliar o testemunho de pessoas especializadas em um determinado assunto, tolerância à ambiguidade, crescimento da sensibilidade para temas polêmicos e habilidade para sistematizar e integrar assuntos, já que a interdisciplinaridade possibilita o cruzamento de distintos saberes.

Bem Viver, da mesma forma, deve ser pensado em um contexto de sociedade a integrar um princípio ético estruturando outra modernidade e apontando a pluralidade da realidade e aprofundando a renovação de pensamento, tanto econômico, cultural, como político, alcançando uma compreensão mais ampla da vida (Farah e Gil, 2012).
O significado de Bem Viver perpassa a simplicidade, reflete a visão holística de povos indígenas em relação ao mundo e a vida, onde se encontram elementos comuns como a harmonia com a natureza, identidade, espiritualidade, reciprocidade, entre outros.

O Foro Permanente para las Cuestiones Indígenas de las Naciones Unidas, na sessão de número 90, em seu informe, declara que os conceitos dos povos indígenas sobre desenvolvimento com cultura e identidade caracterizam-se por um enfoque holístico, tratando de direitos e garantias para o coletivo sobre territórios e recursos. Baseiam-se na tradição e respeito aos antepassados, mas também pensando o futuro. Sua filosofia é sustentada em valores de reciprocidade, solidariedade, equilíbrio, sustentabilidade, intercâmbio e coletividade (Mollo, 2011).

Para colaborar no entendimento do Bem Viver, destaca-se a perspectiva de Vásquez (2011), que a considera como experiência e pensamento dos povos indígenas que servem de ponto de partida inevitável, se desejamos projetar o Bem Viver rumo ao debate de transformação civilizatória e ao diálogo intercultural, onde os desafios não podem ser assumidos pelo pensamento moderno colonial.

Como afirma Wilhelmi (2013), a menção aos povos indígenas faz-se necessária para situar o debate no âmbito da interculturalidade, assim como da plurinacionalidade. De acordo com o autor, desde a invasão colonizadora, a exploração intensiva dos recursos naturais tem gerado graves impactos ambientais e culturais nos países em desenvolvimento. A Constituição Federal do Equador (2008) aponta que o Bem Viver demanda direitos e responsabilidades para pessoas, comunidades, povos e nacionalidades no âmbito da interculturalidade, do respeito às adversidades e da relação harmônica com a natureza.

Bem Viver é uma convivência comunitária com interculturalidade e sem assimetrias de poder, "não se pode viver bem, se os demais vivem mal". Trata-se de viver como parte da comunidade, com sua proteção, em harmonia com a natureza, "viver em equilíbrio com o que nos rodeia (Mollo, 2011: 31). 
A interculturalidade é compreendida pela sua relação com a diversidade cultural e se refere ao encontro entre diversas culturas. Como afirma Walsh (2009), a interculturalidade significa o contato e troca entre culturas de forma igualitária. Estes não devem ser pensados simplesmente em termos étnicos, devem considerar a relação, comunicação e aprendizagem permanentes entre pessoas, grupos, conhecimentos, valores, tradições, lógicas e racionalidades distintas, orientados a gerar, construir e proporcionar respeito mútuo, além de um desenvolvimento pleno das capacidades dos indivíduos e grupos, acima de suas diferenças sociais e culturais.

Na perspectiva do Bem Viver - desenvolvimento humanizado em que a diversidade cultural proporciona responsabilidade e obrigação social na execução da gestão pública - as mudanças que existem na vida pessoal e comunitária, configuram-se em um processo ativo da própria sociedade a tomar suas decisões de maneira coletiva (Mollo, 2011).

De qualquer forma, como afirma Gudynas (2011: 14), é importante ressaltar que, "agrade ou não, o Estado é um espaço estratégico na construção deste conceito, porque é necessário incidir em seu âmago, interagir com os responsáveis de programas e participar ativamente”. Segundo o autor, é necessário relançar as discussões sobre o tema no âmbito da sociedade civil e na sociedade política, pois todos têm a contribuir de modo operativo.

Para Veras Neto e Schneider (2014: 20), “o diálogo intercultural apresenta-se como um verdadeiro 'fórum' para pensar proposições e ações para a manutenção da vida no planeta", o que nos leva a pensar em alternativas ao desenvolvimento.

\section{Bem Viver e alternativas ao desenvolvimento}

O processo histórico da colonização europeia foi constituído em um contexto de dominação cultural, social, econômica e política. À medida que cultura eurocêntrica não respeita a biodiversidade, nem a diversidade cultural, as referências reais e significações simbólicas dos contextos locais são pervertidas.
Para Santos, Meneses e Nunes (2005), a biodiversidade pode ser entendida como uma noção construída por diferentes interesses, onde:

"[...] o discurso sobre a biodiversidade é, de fato, um conjunto de discursos em que se cruzam diferentes conhecimentos, culturas e estratégias políticas. Ainda que essa rede seja dominada por instituições do Norte (organizações não governamentais - ONGs - jardins botânicos, instituições de pesquisa e universidades, empresas farmacêuticas, etc), o conhecimento por elas produzido tem sido também usado de forma 'subversiva', através da sua apropriação por movimentos sociais do Sul e pelos seus aliados e da reinscrição noutras constelações de saber-poder" (2005:61).

Contemporaneamente, boa parte da biodiversidade do planeta existe em territórios dos povos indígenas, para quem natureza é indissociável da sociedade. A preservação desse mundo teve de enfrentar tentativas de destruição, associadas ao colonialismo e, depois, às formas de subalternização características do pós-colonialismo.

Na América Latina está em curso uma renovação da crítica ao desenvolvimento capitalista, na qual embute para a sociedade e maioria dos países a sua sujeição ao econômico. De um lado, ao conservar e reaver uma tradição histórica de questionamentos nesta região, muitas dessas ideais e críticas formuladas no passado, foram deixados para trás e ameaçadas de esquecimento. Por outro lado, as novas concepções estão congregando tanto indagações próprias quanto tomadas de diversas regiões do mundo. Essas contribuições permitiram uma renovação da crítica e também uma melhor adaptação das antigas e novas exigências do século XXI (Acosta, 2014).

Existem também movimentos emergentes que propõem nova concepção para se relacionar com a natureza, como por exemplo a agroecologia. Siliprandi (2012) adverte que a academia precisa dialogar mais 
com os camponeses e camponesas. Para a autora na América Latina existem três áreas distintas da agroecologia. No Brasil se desenvolveu por caminho e história própria; nos Andes, os povos indígenas, convivem com ecossistemas, que exigem convivência com montanhas e clima totalmente adverso; na América Central e México apresentam-se agrossistemas distintos dos anteriores, com outras culturas e próprias histórias. Tanto no México como na região andina, a questão indígena é destaque, onde indígenas e camponeses são quase sinônimos, uma vez que, a agricultura nessas regiões é feita por indígenas.

Nesse contexto, de intercâmbios dos questionamentos, observar-se, que tanto os defensores quanto os que criticam o atual modelo de desenvolvimento neoliberal atuam dentro de seu próprio conhecimento da modernidade ocidental, e várias alternativas recentes surgem dos latino-americanos que vão para além desses limites do conhecimento (Segato, 2014).

O Bem Viver surge em várias regiões do planeta por meio de movimentos que procuram privilegiar e adotar uma outra visão de desenvolvimento que não seja exclusivamente focado na dimensão econômica. Estes movimentos utilizam suas vocações territoriais e procuram de forma coletiva identificar problemas e apontar soluções por meio de esforços dos atores participantes de uma determinada localidade. Até movimentos com um arcabouço mais complexo e de visão mais holística da realidade local buscam favorecer o compartilhamento de afetos e dos elementos que fazem parte da vida das pessoas, como tradição, costume e valores tais como: movimento Bem Viver andino, Slow Cities, Slow Food, Ecovilas, Permacultura, Ecogastromonia, Bem-Estar, Turismo de Base Comunitária entre outros.

A Ecogastronomia é um movimento que defende o uso de ingredientes frescos e sem agrotóxicos ou conservantes químicos, além de valorizar os sabores locais e levar em conta fatores como consciência ambiental, responsabilidade social e biodiversidade agrícola.
Também nesta vertente, surge o movimento BemEstar, que privilegia a qualidade de vida ao provocar um maior equilíbrio entre trabalho e vida pessoal. Conforme Chalofsky e Cavallaro (2013), essa atividade advém das novas gerações localizadas nas grandes cidades que buscam um trabalho significativo com intuito de obter uma vida significativa. Essa com mais tempo a ser utilizado para atividades não relacionadas com trabalho, tais como: lazer, recreativas, esportivas, culturais, lúdicas, relacionais e educativas.

O Slow Cities, assim como o Bem Viver, procura resolver suas dificuldades e propor alternativas ao desenvolvimento de forma participativa por meio do saber local, sem rejeitar o conhecimento científico. Este movimento é abalizado pelo modo de vida, produção, cultura, tradição e conhecimentos locais. A expressão inglesa slow, privilegia a busca por um tempo substantivo, considerando várias outras atividades que não seja exclusivamente econômica. Esse movimento é um modelo alternativo de desenvolvimento que tem sua origem ou desmembramento do movimento slow food, contrapondo ao movimento do fast food pautado na aceleração da vida em função do aumento da produtividade exigido no atual mundo de trabalho (Sampaio, Ceccato, Mendonça e Rehme, 2014).

Dentro destes movimentos, como destacado, o Bem Viver busca reafirmar no pensamento crítico dos ancestrais indígenas, numa outra lógica, a lógica em harmonia com todos os seres e com a natureza, privilegiando a cooperação humana, reverenciando a dinâmica ecossistêmica.

Deste modo, movimentos alternativos como o Bem Viver e as Ecovilas empregam a convivência em comunidades, já o Slow Cities concentra-se em pequenas cidades. Ao mesmo tempo, vêm surgindo movimentos nos grandes centros urbanos, como a Ecogastronomia e o Bem-Estar.

$\mathrm{Na}$ perspectiva do Bem Viver tem-se o reconhecimento do Turismo de Base Comunitária. Solidificado como proposta de escala local, centrado em recursos endógenos (humanos, naturais, culturais 
e de infraestrutura) das comunidades, na solidariedade dos atores envolvidos, vincula-se à promoção da conservação ambiental, valorização da identidade cultural, diversificação econômica nas comunidades receptoras e consequentemente na promoção de uma filosofia de vida que pode ser compreendida como de Bem Viver (Grimm, 2016).

As relações que aproximam os dois temas Bem Viver e o Turismo de Base Comunitária, reside nas origens que fazem emergir a ideia de protagonismo de populações tradicionais/locais/indígenas e seus modos de vidas tão são similares, baseadas no esgotamento do atual modelo de desenvolvimento encampado pela América Latina. Sob esta justificativa, o turismo de base comunitária não é apontado como modalidade nova de turismo, conforme Sampaio (2005), pois se trata de alternativa de promoção de desenvolvimento territorial sustentável.

Finalmente, não se pode negar que o Bem Viver e os movimentos similares que se propagam ao redor do mundo traduzem uma nova concepção de mudança e resistência à postura única e dominante do modo de viver da sociedade capitalista.

\section{Conclusão}

Não se pretende esgotar o tema do Bem Viver neste trabalho, mas possibilitar a construção de um referencial teórico, bem como, apresentar movimentos alternativos ao desenvolvimento e suas aproximações com o Bem Viver como Slow Cities, Slow Food, Ecovilleges, Permacultura, Ecogastromonia, Bem-Estar e o Turismo de Base Comunitária.

As discussões acerca do tema apesar do seu caráter utópico e filosófico, ganham importância como crítica ao paradigma do crescimento econômico ilimitado e que menospreza as dinâmicas socioambientais, superando o modo de produção capitalista.

Ao mesmo tempo, representa uma alternativa ao desenvolvimento onde a subjetividade e o bem comum podem se reconciliar no plano de uma esfera societária que não seja reduzida a mero cálculo e onde o homem não deponha, nem ao outro (política) e nem a si (psique), na produção de um novo caminho que constitui uma vida humana associada que não relegue sistemicamente o seu próprio processo de socialização.

Assim como o Bem Viver, iniciativas e práticas concretas de alternativas ao desenvolvimento evoluem desde uma perspectiva normativa e prática para uma alternativa à crise socioambiental. A diferença epistemológica e ontológica no próprio conceito de desenvolvimento, assim como as diferentes visões e percepções dos sujeitos envolvidos, reforça sua abordagem interdisciplinar, intercultural e sistêmica em direção a um desenvolvimento mais sustentável. Da mesma maneira, a longa história de valorização dos conhecimentos científicos marcou a relação entre as culturas dominantes e dominadas.

Esses conhecimentos têm sido reproduzidos e sistematizados de modo a legitimar a imposição da economia e política europeia globalizante, desde a época da dominação colonial e pós-colonial. É preciso, pois, dar vez e lugar as formas não cientificas de produzir conhecimento sobre meio ambiente, recorrendo e criando espaços de diálogo entre saberes, a fim de reunir as partes que configuram o todo, compreendendo a amplitude das questões ambientais e inspirando para novos questionamentos e outras formas de desenvolvimento. 


\section{Referencias}

Acosta, A. (2014). El Buen Vivir como alternativa al desarrollo.Reflexiones desde la periferia de la periferia. In: Coraggio, J. e Laville, J. (org.). Reinventar la ezquierda en el siglo XXI: hacia un dialogo norte-sur. Buenos Aires: Universidad Nacional de General Sarmiento, pp. 299-312.

Acosta, A. (2014). El Buen Vivir, más allá del desarrollo In: Ramos, G. C.D. (org.). Buena vida, buen vivir: imaginarios alternativos para el bien común de la humanidad. México: UNAM, Centro de Investigaciones Interdisciplinarias en Ciencias y Humanidades. Colección Debate y Reflexión, pp. 21 -60

Almeida, I. M. (2011). Histórico, fundamentos filosóficos e teórico -metodológicos da interdisciplinaridade. In: Phlippi Junior, A. e Silva Neto, A.J. Interdisciplinaridade em ciências, tecnologia e inovação. Manole, Barueri, São Paulo, pp. 04-68.

Alves, C., \& Albuquerque, P. (2013). Bem Viver uma categoria de análise necessária para compreender a vida? In: Markus, C. e Gierus, R. (org.). O Bem Viver na criação. São Leopoldo: Oikos, pp. 155-168.

Bock, C. (2013). Bem Viver na criação de Deus. In: Markus, C. e Gierus, R. (org.). O Bem Viver na criação. São Leopoldo: Oikos, pp. 39-52.

Chalofsky, N., \& Cavallaro, L. (2013). A Good Living Versus a Good Life: Meaning, Purpose, and HRD. Advances in Developing Human Resources, 15 (4), pp. 331 -340.

Coraggio, J. (2014). Presentación de textos latinoamericanos. In: Coraggio, J. e Laville, J. (org.). Reinventar la izquierda en el siglo XXI: hacia un dialogo norte-sur. Buenos Aires: Universidad Nacional de General Sarmiento, pp. 167-174.
Equador. Constitución. (2008). Constitución Política de la República del Ecuador. Disponível em: $<$ http://www.oas.org/juridico/pdfs/mesicic4_ ecu_const.pdf >. Acesso em: 06 abr. 2016.

Farah, I., \& Gil, M. (2012). Modernidades alternativas: una discusión desde Bolívia. In: Martins P. H. e Rodrigues, C. (org.). Fronteiras abertas da América Latina. Recife: Editora da UFPE, pp. 173-202.

Fazenda, I. C. A. (1998). Didática e interdisciplinaridade. (13. ed.), Campinas: Papirus.

Foroni, Y. M. D. (2005). Interdisciplinaridade e multiculturalismo na sala de aula. In: $X$ Seminário Internacional de Educação, 2005, Cachoeira do Sul. Anais. Cachoeira do Sul, Universidade Luterana do Brasil (ULBRA), pp. 01-09.

Gudynas, E. (2011). Buen vivir: Germinando alternativas al desarrollo. Revista América Latina em Movimento, Quito, n. 462, pp.1-20.

Grimm, I.J.; Sampaio,C.A.C. \& Procopiuck M. Arranjo socioprodutivo: organização e gestão das feiras livres na cidade de Curitiba (PR). Anais do IV Encontro de Turismo de Base Comunitária no Cabula e Entorno - ETBCES, Bahia, 2016.

Illich, I. (1978). La Convivencialidad. Ocotepec (Morelos, México). Disponível em: http://www.zorraquino.com.br/textos/ cf-s-ciudades-para-un- futuro/La $\% 20$ convivencialidad.\%20Ivan\%20Linch.pdf. Acesso em: 27 de abril de 2016.

Japiassu, H. (1976). Interdisciplinaridade e patologia do saber. Rio de Janeiro: Imago.

Kapp, K. W. (1963). The social costs of business enterprise. Nottingham: Spokesman Books. 
Leff, E. (1994). Interdiciplinariedad y Ambiente: Bases conceptuales para el manejo sustentable de los recursos. In: Ecologia y Capital. Racionalidad ambiental, democracia participativa y desarrollo sustentable. Mexico: Siglo XXl, pp. 68-123.

Menezes, M. M. (2011). Nos interstícios da cultura: as contribuições da filosofia intercultural. Educação, Porto Alegre, (v. 34), n. 3, p. 324329, set./dez.2011. Disponível em: http:// revistaseletronicas.pucrs.br/ojs/index.php/ faced/article/viewFile/7410/6782 Acesso em: 12 jun. 2015.

Mollo, E. C. (2011). El vivir bien, una propuesta de los pueblos indígenas a la discusión sobre el desarrollo. Obets. Revista de Ciencias Sociales, (v. 6), n. 1, pp. 19-33.

Ortiz, H. (2012). Economía solidaria y pueblos indígenas: desafíos para el buen vivir en la región. In: Lianza, S.; Henriques, F. (org.). A economia solidária na américa latina: Realidades nacionais e políticas públicas. Rio de Janeiro: UFRJ, pp. 87-98.

Quijano, A. A. (2002). Colonialidade do saber. In: Lander, E. (Org.). A colonialidade do saber. Eurocentrismo e Ciências Sociais. Perspectivas latino americanas. São Paulo: Clacso Livros.

Reyna, M. H. (2007). Sobre los sentidos de "multiculturalismo" e "interculturalismo". Revista Ra Ximhai, El Fuerte, (v.3), n.2, pp. 429-442.

Sachs, I. (2007). Ambiente e estilos de desenvolvimento. In: Sachs, I. E Vieira, P. F. (Org). Rumo à ecossocioeconomia: teoria e prática do desenvolvimento. São Paulo: Cortez, pp. 54-76.
Sampaio, C. A. C. (2005). Turismo como fenômeno humano: princípios para pensar a socieconomia e sua prática sob a denominação turismo comunitário. Santa Cruz do Sul: Edunisc.

Sampaio, C. A. C. (2010). Gestão que privilegia uma outra economia: ecossocioeconomia das organizações. Blumenau: Edifurb.

Sampaio, C. A. C.; Ceccato, M.; Mendonça, C., \& Rehme, G. (2014). Slow city: como proposta de desenvolvimento territorial sustentável. II Seminário Internacional Culturas e Desenvolvimento, Chapecó. Anais ..., Chapecó.

Santos, B. (2014). La refundación del Estado en América Latina. In: Coraggio, J. e Laville, J. (org.). Reinventar la ezquierda en el siglo XXI: hacia un dialogo norte-sur. Buenos Aires: Universidad Nacional de General Sarmiento, pp. 281-298.

Santos, B. de S; Meneses, M. P. G., \& Nunes, J. A. (2005). Introdução: para ampliar o cânone da ciência: a diversidade epistemológica do mundo. In: Santos, Boaventura de Sousa (org.). Semear outras soluções: os caminhos da biodiversidade e dos conhecimentos rivais. Rio de Janeiro: Civilização Brasileira.

Segato, R. (2014). La perspectiva de la Colonialidad del Poder y el giro descolonial. In: Coraggio, J.; Laville, J. (org.). Reinventar la ezquierda en el siglo XXI: hacia un dialogo norte-sur. Buenos Aires: Universidad Nacional de General Sarmiento, pp. 175-190.

Vázquez, R. (2012). Towards a Deoclonial Critique of Modernity. Buen

Vivir, Relationality and the Task of Listening. En: Raúl Fornet Betancourt (Ed.), Capital, Poverty, Development, Denktraditionen im Dialog: Studien zur Befreiung und interkulturalität Aachen: Wissenschaftsverlag Mainz, (v. 33), pp. $241-252$. 
Veras Neto, F. Q., \& Schneider, G. S. S. (2014). O ideal de Bem Viver: diálogo e contribuição da cultura milenar dos povos indígenas da América Latina. II Seminário Internacional Imagens da Justiça, Currículo e Educação Jurídica. 2014, Pelotas. Anais.

Thiesen, J. da S. (2008). A interdisciplinaridade como um movimento articulador no processo ensino-aprendizagem. Revista Brasileira de Educação, (v.13), n.39, set./dez.

Walsh, C. (2009). Interculturalidad, Estado, Sociedad. Luchas (de)coloniales de nuestra época. Quito: Universidad Andina Simón Bolívar-AbyaYala.

Wilhelmi, M. A. (2013). Rumo a uma justiça social, cultural e ecológica: o desafio do Bem Viver nas constituições do Equador e da Bolívia. Revista Meritum, Belo Horizonte, (v.8), n.1, p. 313-350, jan. /jun. 